\title{
OS GÊNEROS TEXTUAIS DIGITAIS COMO ESTRATÉGIAS PEDAGÓGICAS NO ENSINO DE LÍNGUA PORTUGUESA NA PERSPECTIVA DOS (MULTI)LETRAMENTOS E DOS MULTILETRAMENTOS
}

\section{DIGITAL TEXT GENRES AS PEDAGOGICAL STRATEGIES IN PORTUGUESE LANGUAGE TEACHING IN THE PERSPECTIVE OF (MULTI) LITERACIES AND MULTILITERACIES}

\section{Jurene Veloso dos Santos Oliveira* Simone Bueno Borges da Silva**}

\section{RESUMO}

Por meio de uma pesquisa bibliográfica, pautada em teóricos específicos, bem como em estudos realizados sob a forma de artigos, teses e dissertações atuais, é proposto, no presente artigo, tecer reflexões teóricas a respeito da necessidade premente de se rever a metodologia utilizada pelos professores de Língua Portuguesa na Educação Básica, sobretudo no Ensino Médio, no qual é possível utilizar/criar/adaptar estratégias pedagógicas que possam usar/integrar/aproveitar as tecnologias digitais, numa perspectiva (multi)letrada e também multiletrada. Para tanto, tem como objetivo precípuo propiciar discussões acerca da inserção dos gêneros textuais digitais, como estratégias pedagógicas, no ensino de Língua Portuguesa, à luz dos (multi)letramentos e dos multiletramentos. Nesse caminho, apresenta as narrativas digitais (digital storytelling) e a microliteratura digital como sugestões de gêneros textuais digitais que podem ser utilizados estrategicamente nas aulas de Língua Portuguesa, no Ensino Médio, a fim de torná-las mais próximas da realidade (ciber) cultural na qual, primordialmente, se insere o aluno desse segmento.

Palavras-chaves: gêneros textuais digitais; (multi)letramentos; multiletramentos.

\section{ABSTRACT}

Through a bibliographical research, based on specific theorists, as well as studies carried out in the form of current articles, theses and dissertations, it is proposed, in this article,

\footnotetext{
* Universidade Federal da Bahia, UFBA, Salvador, BA, Brasil. jurenevelosoadv@gmail.com Orcid: https://orcid.org/0000-0001-5223-1765

** Universidade Federal da Bahia, UFBA, Salvador, BA, Brasil. simonebbs70@gmail.com

Orcid: https://orcid.org/0000-0003-2769-6514
} 
to make theoretical reflections about the urgent need to review the methodology used by teachers of Portuguese Language in Basic Education, especially in High School, in which it is possible to use / create / adapt pedagogical strategies that can use / integrate / take advantage of digital technologies, in a (multi) literate and also multiliterate perspective. In order to do so, its main objective is to promote discussions about the insertion of digital text genres, as pedagogical strategies, in the teaching of Portuguese Language, in the light of (multi) literacies and multiliteracies. In this way, it presents the digital narratives (digital storytelling) and the digital microliterature as suggestions of digital text genres that can be used strategically in the classes of Portuguese Language, in High School, in order to make them closer to the reality (cyber) cultural in which, primarily, the student of this segment is inserted.

Keywords: digital text genres; (multi)literacies; multiliteracies.

\section{INTRODUÇÃO}

O surgimento e o progressivo avanço das tecnologias, sobretudo as digitais, têm influenciado e modificado as formas de comunicação e interação entre os indivíduos nas sociedades, que estão cada vez mais em um contexto cibercultural, principalmente a partir da web 2.0 e da web 3.0, que ressignificaram a forma de acesso e propagação da informação, e, consequentemente, tem havido ampliação e modificação nos modos de ler, de escrever e de comunicar, constituindo, assim, uma nova sociedade leitora, com múltiplas necessidades e possibilidades. Inevitável, portanto, que o ensino e a aprendizagem na Educação Básica também tenham sido afetados, e, em especial, no que diz respeito ao ensino e a aprendizagem de Língua Portuguesa, a qual é constantemente utilizada nos meios virtuais, sob diversas modalidades.

De acordo com Marcuschi (2010), o uso constante por parte dos jovens, em especial os do Ensino Médio (foco do presente artigo), de aparatos tecnológicos, tais como celulares, notebooks, tablets, dentre outros, propiciam o contato com múltiplas linguagens, semioses, ambientes virtuais e oferecem uma infinidade de gêneros textuais digitais, que daí emergem. Importante, pois, que isso seja aproveitado, articulado enquanto estratégias pedagógicas por parte dos professores de Língua Portuguesa, a fim de tornar as aulas mais próximas da realidade social/cibercultural, e fazer com que os alunos usem a língua de forma significativa, construindo-se, desse modo, caminhos para que a aprendizagem ocorra processualmente, de forma coletiva e, principalmente, colaborativa. Necessário, pois, uma postura diferenciada do professor em relação ao conhecimento e a sua concepção de ensino.

Nesse pensamento, afirmando essa necessidade de uma nova postura do professor e, portanto, de uma nova pedagogia, Couto (2014) afirma que, 
tradicionalmente, ainda persiste o modelo de ensino centrado no professor, de forma hierarquizada e padronizada, o que faz com que o aluno fique isolado do processo de aprendizagem e chama a atenção para a necessidade desse profissional adaptar-se às demandas atuais.

Logo, no espaço da sala de aula, é preciso trazer o virtual, o cibercultural, o digital, de forma estratégica, organizada a fim de se chegar a objetivos que se pautem, prioritariamente, na reflexão crítica e na produção autoral a partir do ensino e da aprendizagem de Língua Portuguesa.

Oliveira (2018), em sua dissertação de mestrado, observou que, na prática, no cotidiano da escola, as tecnologias digitais e seus diversos usos/possibilidades pouco têm sido utilizados na sala de aula, por diversos motivos, que vão desde a insuficiência de recursos materiais na instituição de ensino, até a não fluência digital/insegurança/receio por mudanças na metodologia de ensino por parte dos professores. Comumente, nesse contexto, esses se utilizam tão somente de formas/ recursos tradicionais de ensino como livros didáticos, quadro branco, piloto e xerox em preto e branco. Tais recursos, obviamente, não precisam ser descartados, mas é preciso que se faça uso também dos meios possibilitados pelas tecnologias digitais, tornando as aulas mais interativas e em conexão com uma sociedade que é cada vez mais virtual e cibercultural (Lévy, 2010).

Desse modo, torna-se relevante pensar em estratégias pedagógicas ${ }^{1}$ voltadas à aplicação prática, na sala de aula, de atividades que integrem meios tecnológicos digitais com maior frequência, que possam fazer com que o interesse do aluno se amplie, e se chegue a resultados satisfatórios, principalmente em relação à Língua Portuguesa, que pode ser usada, enquanto princípio, meio e fim na busca e na apropriação do conhecimento. Atividades com gêneros textuais digitais, os quais são definidos por Marcuschi (2010) como modalidades discursivas que surgem a partir da operação com softwares e seus processos interativos, podem ajudar significativamente. Como exemplos desses gêneros, dentre muitos outros, estão a narrativa digital (digital storytelling) e a microliteratura digital (minicontos, microcontos, nanocontos e twitcontos) que podem servir como mote para o desenvolvimento de habilidades linguísticas e cognitivas do aluno do Ensino Médio, num viés crítico e reflexivo.

O ensino de Língua Portuguesa, na escola, precisa estar atrelado a situações que combinem o desenvolvimento das habilidades linguísticas (ler, falar, escrever, ouvir), com o uso das tecnologias digitais. O professor necessita, então, ir além da

1. Estratégias pedagógicas, aqui, têm o sentido de abarcar metodologias, atividades e recursos didáticos que possibilitem e potencializem o ensino e a aprendizagem de Língua Portuguesa. 
teoria e pensar na criação de práticas pedagógicas que promovam a apropriação daquilo que é disponibilizado a partir dos ambientes virtuais, no processo de ensino e aprendizagem de Língua Portuguesa, na intenção de se construir um ambiente educacional mais criativo e "conectado" com o cotidiano dos jovens, sobretudo os do Ensino Médio. Tudo isso poderá contribuir para que haja uma relação dialógica (BAKHTIN, 2003), mais significativa entre os principais atores da Educação: professores e alunos, por meio do uso crítico das tecnologias, as quais devem ser pensadas enquanto processo de conhecimento.

É relevante destacar que, tanto a Lei de Diretrizes e Bases da Educação (LDB - Lei n. 9.394/96), quanto as Orientações Curriculares para o Ensino de Língua Portuguesa no Ensino Médio (2006) apontam para a necessidade de inserir as tecnologias digitais na sala de aula. Porém, é preciso ressaltar que, não basta aprender a usar os meios tecnológicos digitais de forma mecânica, mas sim, é preciso que haja reflexão crítica e coletiva acerca de seus usos na Educação, de forma a embasar posicionamentos, iniciativas, novos percursos, enfim, ressignificar suas ações, tanto por parte dos professores quanto dos alunos.

Ainda, conforme exposto nos Parâmetros Curriculares Nacionais (PCN) (1999), é preciso haver articulação entre três fatores para que aconteça o aprendizado de Língua Portuguesa: 1- a ação do aluno sobre o objeto do conhecimento; 2- os conhecimentos discursivos textuais e linguísticos implicados nas práticas sociais da linguagem e; 3 - a mediação do professor, cuja função é de organizar situações de aprendizagem.

É importante, também, que haja um estudo das propostas advindas da Base Nacional Comum Curricular², a qual, em suas competências e habilidades, no que concerne à área de Linguagens e, em especial, ao ensino de Língua Portuguesa, enfatiza a necessidade de integração das tecnologias digitais ao ensino e à aprendizagem (BNCC, 2017)

Nesse caminhar, a relação ensino-aprendizagem de Língua Portuguesa pode dispor de múltiplas semioses, surgindo então, uma infinidade de maneiras de usála de forma efetiva, significativa, crítica e reflexiva. O estudo dos gêneros textuais digitais emergentes (MARCUSCHI, 2010) servirá, a priori, como potencializador do trabalho do professor de Língua Portuguesa no desenvolvimento das habilidades linguísticas desejadas no segmento do Ensino Médio.

Rojo e Barbosa (2015) demonstram grande preocupação pelo fato dos estudantes da Educação Básica, apesar de passarem tanto tempo na escola, apresentarem, frequentemente, resultados insatisfatórios quanto ao uso da Língua

2. Documento homologado pela Portaria n 1.570, publicada no D.O.U. de 21/12/2017, Seção 1, pág. 146. 
Portuguesa, o que tem sido constatado através de avaliações externas oficiais, a exemplo daqueles demonstrados no Sistema de Avaliação da Educação Básica (SAEB), no Exame nacional do Ensino Médio (ENEM) e na Prova Brasil.

De forma contraditória a esses resultados oficiais, os alunos se comunicam constantemente através da Língua Portuguesa, seja na forma oral ou na escrita, seja nos espaços físicos ou virtuais, fazendo uso das habilidades linguísticas, participando/ integrando de/a cultura digital que permeia a sociedade atual; usam computadores, dispositivos móveis com múltiplas funções, tais como celulares ou smartphones com acesso à internet, e, por meio deles, utilizam aplicativos, participam de redes sociais, pesquisam de acordo com seus interesses, produzem textos semióticos, que combinam linguagens híbridas, com imagens, sons; produzem memes, publicam fotos, comentam, curtem, tecem reflexões críticas etc., e "querem" e "necessitam" usar todo esse conhecimento no ambiente escolar/instituição de ensino (OLIVEIRA, 2018).

Desse modo, percebe-se que há a necessidade de se rever a metodologia utilizada pelos professores de Língua Portuguesa na Educação Básica, sobretudo no Ensino Médio, utilizando/criando/adaptando estratégias pedagógicas que possam integrar as tecnologias digitais, numa perspectiva mais ampla, a exemplo do uso dos gêneros textuais digitais, os quais podem ajudar na compreensão das múltiplas formas/possibilidades de acesso ao conhecimento, de forma crítica, reflexiva e situada. Nesse sentido, o objetivo precípuo pretendido neste artigo é propiciar discussões acerca da inserção dos gêneros textuais digitais, como estratégias pedagógicas, no ensino de Lingua Portuguesa, à luz dos (multi) letramentos e dos multiletramentos.

Trata-se de uma pesquisa bibliográfica, pautada em teóricos específicos, bem como em estudos realizados, especialmente, sob a forma de artigos, teses e dissertações atuais, que podem ajudar a compreender e fundamentar temas que remetam ao ensino de Língua Portuguesa em um contexto cibercultural, (multi) letrado e multiletrado, influenciado pelo uso (direto e/ou indireto) das tecnologias digitais, sobretudo a partir do uso dos gêneros textuais digitais, a serem pensados enquanto estratégias pedagógicas no segmento do Ensino Médio.

Para tanto, o presente artigo está dividido em quatro capítulos. Após este primeiro capítulo introdutório, há o capítulo dois, destinado a discorrer sobre o termo (multi)letramentos, em contraponto a outro termo, semelhante na escrita, porém diferente em seu teor, referindo-se aos multiletramentos. Já, no terceiro capítulo, buscou-se trazer uma compreensão acerca do que são, de fato, estratégias pedagógicas, aliando seu entendimento à ideia da aplicabilidade dos gêneros textuais digitais. Neste, são propostos dois tipos de gêneros textuais digitais: as 
narrativas digitais (digital storytelling) e a microliteratura digital, que poderão servir como potencializadores do ensino e da aprendizagem de Língua Portuguesa, no segmento do Ensino Médio, desde que estruturados estrategicamente. Por fim, no último capítulo, de número quatro, são feitos os arremates estratégicos finais, no qual se buscou tecer considerações gerais sobre o que se propôs ao longo deste texto.

\section{1. (MULTI)LETRAMENTOS: ARTICULANDO CONCEITOS}

De acordo com Magda Soares (2002), ser alfabetizado não é condição para tornar o indivíduo letrado. Logo, um não é conditio sine qua non para o outro. Conforme a autora, a alfabetização trata da aquisição do sistema de escrita, abrangendo o alfabeto, as sílabas, as palavras, decodificação de signos etc.; o letramento, por sua vez, remete "às práticas sociais de leitura e escrita", o que não obriga, necessariamente, que o indivíduo deva ser alfabetizado, bastando, então, que ele vivencie "eventos de letramento", em níveis variados, na sociedade em que se insere, conforme explicitado por Kleiman (1995). Entretanto, não se pode negar que, em virtude da sociedade ser, sobretudo, grafocêntrica, se esse indivíduo for alfabetizado, isso o auxiliará em seu processo contínuo de letramento. Logo, é inegável afirmar que, saber ler e escrever sempre será algo a mais, um diferencial.

O termo letramento, na verdade, atrela-se também à concepção de alfabetização, porém, vai além. Etimologicamente, letramento provém do latim littera (letra), acrescida do sufixo - cy, o qual dá origem à palavra inglesa literacy, que, no Brasil, passou a significar "[...] o estado ou condição que assume aquele que aprende a ler e a escrever". Ler e escrever, nesse espaço, alinha-se a questões "sociais, culturais, políticas, econômicas, cognitivas, linguísticas, quer para o grupo social em que seja introduzida, quer para o indivíduo que aprenda a usá-la" (SOARES, 2005, p. 17).

Logo, infere-se que, no ato da escrita, relacionam-se processos de cunho interacional e relacional humanos. Portanto, "[...] alfabetização e letramento são processos que devem ocorrer de modo simultâneo" (TFOUNI apud SILVA, 2008, p. 221). Isso seria o ideal, pois o indivíduo pode/poderia tornar-se mais independente na sociedade, podendo se inserir nos eventos de letramento que ocorrem na sociedade, de forma mais completa, a fim de que assim consiga "participar das práticas discursivas materializadas pelos diversos gêneros textuais que circulam na sociedade letrada" (SILVA, 2008, p. 221). 
É esperado, na verdade, que a alfabetização ocorra de forma contextualizada com a realidade do indivíduo/aluno em meio à sociedade que integra. Desse modo, o letramento (especialmente o escolar) poderá conduzi-lo a uma inserção social, possibilitando-lhe o exercício de seus direitos e deveres na sociedade da qual faz parte, pois "esta é erigida em torno de espaços de interação que exigem o conhecimento de pessoas letradas, que dominam, principalmente, a escrita e a leitura, de forma ampla, concreta" (OLIVEIRA, 2018, p. 62). Logo, privilegia-se, principalmente, o letramento aprendido/apreendido no espaço escolar, o chamado letramento escolar, que seguem estruturas/exigências determinadas.

Tecendo críticas aos modelos de letramento escolar, tão valorizados socialmente, Street (2014) alerta para questões de ordem política que lhes são subjacentes. Privilegiam-se a escrita e a leitura formal, dentro de padrões rígidos, ensinadas de maneira funcional. $\mathrm{O}$ autor chama esse tipo de letramento de "autônomo" e o diferencia de outro tipo que ele denomina de "ideológico" (STREET, 2014). Conceituando o letramento autônomo, o autor afirma que este se trata de

[...] um conjunto separado, reificado de competências "neutras", desvinculado do contexto social - e nos procedimentos e papeis sociais por meio dos quais esse modelo de letramento é disseminado e interiorizado (STREET, 2014, p.129).

Nesse sentido, o autor realiza crítica a esse modelo interpretativo autônomo, o qual "reduz o letramento a um conjunto de capacidades cognitivas, que pode ser medido nos sujeitos" (STREET, 2014, p. 130). Tal concepção apresenta alguns termos comumente usados como, por exemplo: grau de letramento, nível de letramento ou baixo letramento, os quais revelam essa concepção autônoma, centrada no sujeito e nas capacidades de usar apenas o texto escrito. O sujeito, efetivamente letrado, vai muito além da escrita, conseguindo alcançar inclusive o que está antes, por trás ou ao lado do que se registra graficamente.

No modelo ideológico, em confronto ao autônomo, a ideia adjacente é a de que é necessário "compreender o letramento em termos de práticas concretas e sociais" (STREET, 2014, p. 09). Desse modo, não basta privilegiar um determinado tipo de letramento, tido como superior, ou dominante, e exigir certos aprendizados puramente formais, sem sentido, sem significação para o indivíduo. E, isto, na prática, é o que, não raro, tem acontecido nos espaços formais de aprendizagem, principalmente no que concerne ao ensino e à aprendizagem de Língua Portuguesa.

Um termo que pode ser facilmente confundido com os diversos tipos de letramentos existentes, que aqui foi preambulado como (multi)letramentos, é multiletramentos, o qual traz, em seu bojo, outras perspectivas, mais amplas e diversas. 


\subsection{Multiletramentos: compreendendo um conceito}

Para abordar sobre os multiletramentos faz-se necessário remeter à denominada "pedagogia dos multiletramentos", a qual é resultante de um colóquio realizado pelo Grupo de Nova Londres (GNL), em Nova Londres, em 1996, em Connecticut (EUA), formado por vários pesquisadores que discutiam os letramentos. Nesse espaço, foi publicado o manifesto "A Pedagogy of Multiliteracies - Designing Social Futures" (Uma pedagogia dos multiletramentos - desenhando futuros sociais), no qual se discutiu acerca da necessidade da escola inserir os novos letramentos nos currículos, que estão presentes já há algum tempo na sociedade contemporânea, sejam estes trazidos pelo uso das tecnologias ou decorrentes de outras linguagens e culturas (Rojo \& Moura, 2012, grifo nosso).

Inicialmente, a ideia dos multiletramentos se constituiu a partir da consideração de que existem muitos problemas de ordem social que influenciam no aumento da violência e, consequentemente, na falta de perspectiva futura para os jovens, que precisavam ser discutidos, sobretudo nos países que convivem com conflitos culturais, como "lutas entre gangues, massacres de rua, perseguições e intolerância" (Rojo \& Moura, 2012, p.12).

Outra situação emergente que moveu o Grupo de Nova Londres foi que os jovens contavam com "[...] outras e novas ferramentas de acesso à comunicação e à informação e de agência social, que acarretavam novos letramentos, de caráter multimodal ou multissemiótico (Rojo \& Moura, 2012, p. 12-13)". Daí, então, surgiu o termo multiletramentos, o qual se disseminou entre os estudiosos da Educação em diversos países, e, dentre estes, o Brasil, o qual tem discutido, até os dias atuais, sobre suas concepções e possibilidades.

Os problemas apontados pelo Grupo de Nova Londres fazem parte da realidade aqui no Brasil, em virtude dos conflitos sociais decorrentes, sobretudo, das desigualdades socioeconômicas, ou por conta de diferenças e variações linguísticas e regionais, dentre outros fatores.

Percebe-se, cotidianamente, que a linguagem utilizada no ambiente escolar tem se mostrado, em muitos casos, distante da realidade da sociedade contemporânea, a qual perpassa cada vez mais pelo uso das tecnologias digitais, o que, por sua vez, provoca a necessidade de se pensar acerca dos multiletramentos, não apenas no campo teórico, mas, também, no campo da prática, que deve estar inserida na atuação do docente em sala de aula. Então, ao professor ${ }^{3}$, cada vez mais

3. É fato que, não é apenas responsabilidade do professor a busca por inovações na relação ensino e aprendizagem; cabe ao sistema educacional como um todo, abrangendo todos os atores envolvidos nesse mister, propiciando formação e oferecendo recursos, a fim de viabilizar atualização constante e ampliar a qualidade na Educação. Entretanto, o foco do presente artigo centra-se na figura do professor e em sua capacidade de produzir aulas que viabilizem a formação de um sujeito essencialmente crítico. 
se torna necessário atualizar-se, buscando descobrir novas possiblidades de renovar sua prática, de forma que consiga abarcar as múltiplas linguagens dos alunos, os quais, em sua maior parte, fazem parte da chamada geração "Z" $Z^{\prime 4}$. Não é tarefa simples. Mas, se não se reinventar, o professor passará pelo risco de perder sua função social, deixando de ser visto enquanto profissional de fato necessário às demandas da sociedade.

Tratando dos multiletramentos e do papel e da formação do professor, em uma sociedade que é digital, queira-se ou não, Silva (2017) afirma que, em decorrência da virtualidade dos meios tecnológicos, é preciso pensar em novas maneiras de pensar e agir no mundo, pois

[...] Vive-se uma revolução tecnológica informacional, de caráter transgressor, que leva à reflexão, a necessidade de se viabilizar práticas de letramentos que conduzam crianças e jovens a uma leitura e interpretação crítica dos fatos da vida, de suas aprendizagens, de modo a compreenderem que seus conhecimentos e saberes, ideias e ações afetam o mundo, transformando-o em outro mundo possível, um mundo que avança, aceleradamente, para o ciberespaço (SILVA, 2017, p. 215, grifo nosso).

Nesse sentido, pois, não há mais espaço para a figura do professor "detentor de conhecimentos"; ; cabe-lhe, na verdade, aprimorar suas práticas, seus saberes que o conduzam a intermediar os conhecimentos, fazendo com que os alunos ajam com criticidade diante da realidade que os cerca. Ainda, esse mesmo professor precisa lidar com a diversidade, com a heterogeneidade de suas classes de alunos, os quais possuem histórias, interesses e leituras de mundo (Freire, 1987) distintas, lidando com questões identitárias e de mundo (HALL, 2006).

Com os multiletramentos, enfim, abrem-se múltiplos caminhos para um novo olhar e novas formas de atuar do professor a fim de propiciar aos alunos o uso de diversos recursos semióticos em situações de comunicação e interação, possibilitando, antes de tudo, uma compreensão crítica perante os acontecimentos a sua volta.

\section{ENTENDENDO 0 QUE SÃO ESTRATÉGIAS PEDAGÓGICAS}

De acordo com Bzuneck (2010), quando se alude a estratégias pedagógicas, refere-se a uma variedade de recursos e atividades que são propostas a fim de

4. O termo geração "Z" alude às pessoas que nasceram, em média, entre 1990 e 2010, sucedendo à geração Y (que abrange, em média, os nascidos a partir de 1982). Vivem conectadas, usam tecnologias digitais modernas, tudo de forma mais natural, pois tudo isso faz parte de sua geração. Ressalte-se, porém, que, especialmente por questões de desigualdades sociais existentes no Brasil, nem todos os jovens dessa geração estão incluídos digitalmente. 
assegurar motivação para que a aprendizagem do educando ocorra efetivamente. Assim, o docente, ao aplicar estratégias pedagógicas, deve valorizar tarefas de aprendizagem, indicar/elaborar pistas cognitivas que levem à resolução das atividades propostas, bem como deverá reconhecer o esforço e a dedicação empenhados pelo estudante; deve, ainda, ser comprometido ao organizar e preparar suas aulas e formas de avaliação. Logo, ao se falar em estratégias pedagógicas aludese às metodologias, atividades e recursos didáticos que possibilitam e potencializam o ensino e a aprendizagem.

Entretanto, conforme importante alerta feito por Simone B.B. Silva (2019), é preciso ter cuidado para não incorrer na mera substituição de métodos antigos (tipográficos, analógicos, dentre outros) por métodos tecnológicos, sendo necessário, pois, "[...] desenvolver, metodologicamente, práticas de linguagem que consideram essa maneira específica de ver o mundo e de estar nele" (SILVA, 2019, p. 195). Em outras palavras, não basta trocar "seis por meia dúzia"; é preciso haver sentido e objetivos bem definidos na escolha do meio tecnológico a ser usado na aula, devidamente aliado ao conhecimento a ser discutido/construído.

Para o ensino de Língua Portuguesa, como estratégia pedagógica, o professor pode fazer uso, em suas aulas, da inserção de gêneros textuais digitais diversos como forma de articular a aprendizagem de temas voltados à ampliação e ao aprimoramento da escrita e da oralidade da língua, utilizando-se de uma concepção de ensino de língua abrangente, aberto e flexível, não preso a conteúdos fechados. É importante que se privilegiem estratégias que promovam a criticidade, a participação e a construção do conhecimento por parte do aluno. Na verdade, a estratégia pedagógica principal usada pelo professor de Língua Portuguesa deve ser a de promover espaços de reflexão, que ajudem o aluno a pensar e a usar efetivamente sua língua, se familiarizando cada vez mais com ela, indo muito além do estudo de sua estrutura funcional, afinal trata-se de sua língua matter.

\subsection{Os gêneros textuais digitais como estratégias pedagógicas}

É inegável que o avanço tecnológico tem afetado a sociedade e provocado modificações nas atividades linguístico-cognitivas dos usuários (interagentes) e consequentemente, afetam também o "processo ensino/aprendizagem da língua na escola e fora dela" (Marcuschi, 2010, p. 11). Nesse espaço, surgem os chamados gêneros textuais digitais, os quais são frequentemente usados socialmente pelos indivíduos.

Marcuschi (2010) indica três aspectos que justificam a análise dos gêneros textuais digitais, dentre estes estão: 1- o seu livre desenvolvimento e uso de forma 
mais generalizada, 2 - suas características específicas, apesar de terem contrapartes em gêneros já existentes $e_{i} 3$ - permitir que se revejam conceitos tradicionais, trazendo um novo olhar para a relação oralidade e escrita. O autor afirma, ainda, que o tema gêneros textuais vem sendo tratado desde os anos 60 , a partir do surgimento da Linguística de Texto, a Análise Conversacional e a Análise do Discurso.

Marcuschi (2010, p. 19) traz uma definição e um alerta sobre gêneros textuais: "[...] são formas sociais de organização e expressões típicas da vida cultural. Contudo, os gêneros não são categorias taxinômicas para identificar realidades estanques". Ou seja, novos gêneros vão surgindo dentro da sociedade sob novos contextos, novas criações humanas. Os gêneros textuais digitais são, assim, fruto de mudanças na maneira como as pessoas têm se estruturado e se expressado.

Como exemplos de alguns gêneros textuais digitais, que emergiram dos ambientes digitais, Marcuschi (2010) cita: e-mail ${ }_{i}$ chat em aberto; chat reservado; chat agendado; chat privado; entrevista com convidado; e-mail educacional; aulachat; videoconferência interativa; lista de discussão; endereço eletrônico; web blog (blogs, diários virtuais). O autor lembra que o ambiente virtual pode tornar obsoletos alguns gêneros em curto espaço de tempo, e propiciar o surgimento de novos. Importante, pois, contínua atualização por parte dos usuários (interagentes). Entretanto, ainda que ocorram mudanças, há que se preservar a relação dialógica, proposta por Bakhtin (2003), segundo o qual os textos se formam e se complementam um no outro, de forma "intertextual e polifônica". Desse modo, Marcuschi (2010) alerta para o fato de que os gêneros textuais digitais, em geral, surgem a partir de outros gêneros textuais, tradicionais, que vão mudando de suporte, de formas, e influenciam, consequentemente, nas relações e na comunicação entre as pessoas.

Atualmente existem as redes sociais (Facebook, WhatsApp, Instagram, Twitter, dentre outras, que abarcam uma infinidade de gêneros, como as mensagens instantâneas (os posts), por exemplo, que podem ser usadas em linguagem formal ou informal. Até mesmo as abreviações usadas nos ambientes virtuais, sobretudo nas redes sociais, tão criticadas por muitos professores e estudiosos, que fazem parte do denominado "internetês" (a exemplo: blz, kd, naum, bisc8, ta, xau, vc, ss etc), têm um resquício da forma como eram redigidas as mensagens enviadas via telegrama. Constata-se que a finalidade da economia de palavras nos telegramas dava-se por questão pecuniária, pois o serviço era cobrado por letra e palavras emitidas; no ambiente virtual, sobretudo em situações informais, a economia de letras ocorre devido à necessidade de responder rapidamente, daí, usam-se os emojis, por exemplo, que, muitas vezes, substituem palavras e expressam sentimentos (MARCUSCHI, 2010). 
Paiva (2016), partindo da compreensão de que a linguagem, na verdade, é um sistema adaptativo complexo, o qual está em constante processo de transformação, aponta para os impactos causados pelas tecnologias de comunicação digital na interação humana, sobretudo em tempos de uma comunicação permeada pelo uso de tecnologias móveis, que provocam modificações na linguagem. Como exemplo desse fenômeno, a autora, assim como Marcuschi (2010), aponta para o uso de emojis (que representam emoções humanas no ambiente virtual) e de stickers (os quais servem para representar emoções humanas nos espaços virtuais). Esses elementos virtuais podem assumir funções discursivas variadas, a depender do contexto e finalidade em que são utilizados, podendo substituir palavras, expressar emoções, indicar afeto, assumir a função de intensificador ou para expressar ironia. Além disso, costumam apresentar regularidades sintáticas, como a posição em que aparecem na mensagem, a ordem em que são inseridos, dentre outros aspectos, sinaliza a autora.

Assim, é inegável que o espaço virtual oferece amplas possibilidades de uso da linguagem, refletindo culturas e trazendo inovações na arte de se comunicar, oportunizando a interação humana de formas múltiplas. Nesse espaço, os gêneros textuais digitais fazem parte da sociedade atual, que é tecnológica, virtual e cibercultural. Nesses, a língua faz-se presente constantemente, sobretudo em sua forma escrita, e isso deve ser devidamente aproveitado e inserido nas aulas de Língua Portuguesa.

\subsection{Criando estratégias pedagógicas: em cena os gêneros textuais digitais}

A partir da inserção dos gêneros textuais digitais, acredita-se que seja possível ao professor de Língua Portuguesa organizar aulas voltadas, sobretudo para a leitura, análise e produção textual por parte do aluno, permitindo-lhe o uso real, efetivo de sua língua em sala de aula. Como descrito anteriormente, são inúmeros os tipos de gêneros textuais existentes na cibercultura, oriundos a partir do avanço das tecnologias digitais, principalmente a partir do World Wide Web (www) ${ }^{5}$ que propiciou a propagação da informação e a comunicação em larga escala.

Mas, de que forma os gêneros textuais digitais podem ser inseridos no cotidiano da sala de aula, em especial, nas aulas de Língua Portuguesa? A seguir são abordados dois tipos de gêneros que podem vir a ser explorados por parte dos professores de Língua Portuguesa, que podem se interessar em fazer uso deles em

5. O World Wide Web (WWW) refere-se à rede mundial de computadores, e designa um sistema de documentos em hipermídia (hipermédia) que são interligados e executados na Internet (CARVALHO, 2006). 
seus planos de aulas, tornando-as mais atrativas e (re) significativas: a narrativa digital (digital storytelling) e a microliteratura digital.

\subsubsection{0 gênero narrativa digital (digital storytelling) ${ }^{6}$}

Dentre os gêneros textuais digitais que têm surgido no contexto da cibercultura e que têm provocado novas possibilidades de acesso ao conhecimento, há o gênero narrativa digital (digital storytelling), o qual é bem definido por Carvalho (2008, p. 87), quando diz que trata-se de um "[...] processo de produção textual que assume o carácter contemporâneo dos recursos audiovisuais e tecnológicos capazes de modernizar 'o contar histórias' ". Logo, tais produções, feitas em ambiente virtual, ou a partir dele, podem se tornar estratégias, meios pedagógicos eficientes, que irão motivar o aluno e potencializar seu aprendizado.

Por meio de tal gênero, é possível realizar a contação de histórias a partir do uso de meios tecnológicos, sobretudo com acesso à internet. Através de uma narrativa digital (digital storytelling) é possível fazer uso de diversas habilidades linguísticas e cognitivas ao realizar a leitura, a escrita e a oralidade por meio de narrativas, de forma coerente e coesa. Em sala de aula, tal gênero pode ser utilizado como uma estratégia em diversos formatos, possibilitando a criatividade e a interação social, associando linguagens em sua forma verbal ou não-verbal, formando-se, ao final, textos híbridos. Tais histórias, ressalte-se, podem ser criadas e recriadas inserindose temas voltados aos interesses e necessidades dos alunos, levando-os, a exemplo, a refletirem sobre seu papel enquanto cidadão ou sobre a comunidade em que vive.

Os alunos, em sua maioria, além dos tablets, notebooks etc., possuem um artefato digital, quase que indispensável atualmente: o smartphone. Este agrega múltiplas funções: acesso às redes sociais (Facebook, WhatsApp, Twitter, Instagram, etc), a sites e blogs diversos, jogos, uso de câmeras fotográficas e de vídeos, gravação de áudio; essas e outras funcionalidades podem permitir a participação ativa em construções de narrativas variadas, de forma autoral, individual e/ou coletivamente, criando e recriando histórias. Além disso, apresentam-se como artefatos cada vez mais ubíquos, podendo, assim, ser usados em todo lugar, a qualquer tempo.

Acerca da arte de contar histórias, interessante o pensamento de Kieling (2012, p. 744), ao remeter a sua universalidade e formas diferentes e contextualizadas de realizá-la, pois "As histórias são universais, mas a maneira de contá-las muda de acordo com o meio de transmissão, as condições de recepção e a mídia utilizada,

6. Neste artigo, são usados os termos em inglês e português: narrativas digitais e digital storytelling, indistintamente. 
já que cada uma tem suas próprias características, janelas espaciais e temporais [...]". Como elementos-chaves da narrativa, também presentes na digital storytelling, pode-se elencar o enredo, os caracteres, a elocução e o pensamento, dentre outras características peculiares ao ambiente digital (KIELING, 2012).

De acordo com Valente e Almeida (2014), por meio da narrativa digital, é possível envolver o leitor, percorrendo-a em diferentes caminhos, de acordo com seu interesse e as ligações deixadas pelo autor. E, desse modo,

[...] o autor tem a oportunidade de compartilhar suas experiências, receber feedback, rever e reformular suas trajetórias e produções, ao mesmo tempo em que o leitor pode tomar tais narrativas como referência para elaborar e reconstruir suas histórias (Valente e Almeida, 2014, p. 37).

Logo, por meio de narrativas digitais, viabiliza-se a criação de oportunidades de produção autoral e de interação entre autor e leitor, articulando-se as múltiplas semioses que habitam o espaço virtual. $\mathrm{Na}$ imagem a seguir são apresentados os passos para se construir uma narrativa digital, a título de exemplo:

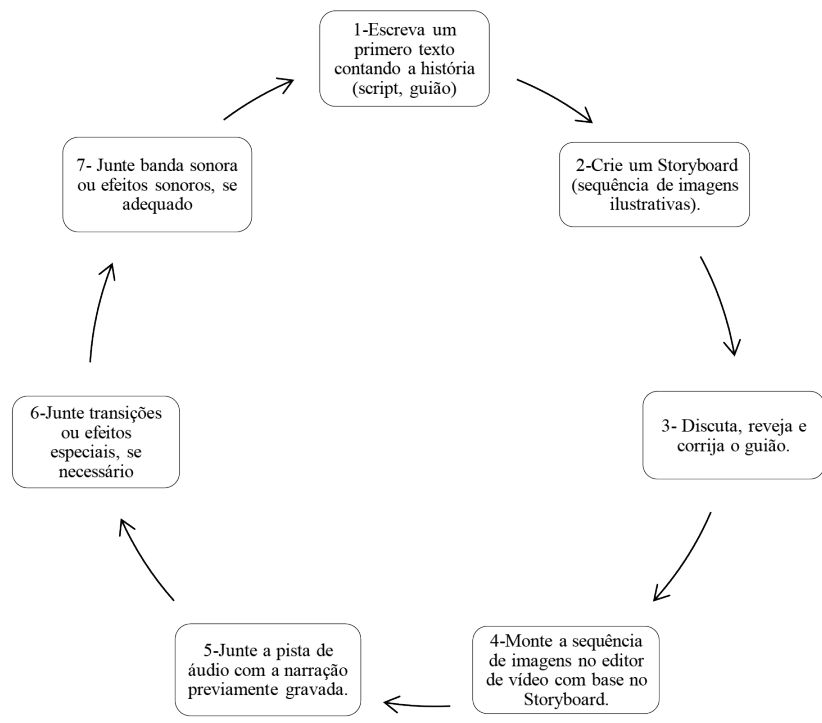

Figura 1. Etapas de construção de uma narrativa digital

Fonte: Adaptado de COSTA (2016). Disponível em:

$<$ http://aprendercom.org/comtic/?p=1109> Acesso em: 15 out. 2019.

Como se pode observar das etapas descritas acima, é possível associar múltiplas linguagens, como a sonora e a imagética, ao se construir narrativas 
digitais, mas, a principal contribuição desse gênero textual digital nas aulas de Língua Portuguesa, é o aguçamento da curiosidade e da criatividade que, por sua vez, contribuirão, de forma especial, para o poder de criticidade e de reflexão, que devem permear efetivamente o espaço do ensino e da aprendizagem.

Trazendo mais aportes acerca das narrativas digitais, Valente e Almeida (2014), esclarecem que essas não se tratam de construções, ideações livres, pois englobam o saber, a racionalidade e a identidade acerca da forma como as pessoas concebem o mundo; hoje, existem diversas pluralidades de narrativas digitais, como por exemplo, as narrativas de cunho interativo, as histórias e relatos digitais, as narrativas multimídias ou narrativas multimidiáticas. Logo, tal gênero pode ser utilizado no ensino de Língua Portuguesa, auxiliando na concretização de uma relação de ensino e aprendizagem mais significativa. Para tanto, é preciso, a priori, criatividade, sensibilidade e definição de objetivos por parte do professor, ao organizar suas aulas e estabelecer suas estratégias pedagógicas.

\subsubsection{0 gênero microliteratura digital: microconto/miniconto/nanoconto/ twitconto}

\footnotetext{
"Queria que o pai comprasse um novo porque o outro morreu. Irmãos não são vendidos em lojas, filho" (Rossatto, 2010).
}

A microliteratura digital (também denominada micronarrativa digital) engloba diversos tipos de produções e, dentre essas, estão aquelas surgidas no ambiente virtual, como o microconto, o miniconto, o nanoconto e o twitconto. Todos têm algo em comum: servem para contar histórias de forma curta, direta, resumida, porém, com amplo alcance e significado, a depender da intenção de quem escreve e de quem os lê. Rocha (2013, p. 25), em seus estudos sobre o microconto, afirma que: "Quanto mais concentrado, mais se caracteriza como arte sugestão, resultante de rigoroso trabalho de seleção e harmonização dos elementos selecionados e de ênfase no essencial".

Dentro do gênero miniconto, em virtude dos ambientes virtuais e do acesso a todo tipo de construção literária e formas de comunicação que fazem surgir novos gêneros, aparecem, então, o que Rocha (2013) chama de "microliteratura". Nesta, há, pois, os microcontos (possuem até 150 toques, incluindo letras, espaços e pontuação), minicontos (contêm 300 palavras ou 600 caracteres), nanocontos (até 50 letras, sem espaços e acentos), twitcontos (até 140 caracteres).

O microconto abarca uma história em prosa narrada em cinquenta letras ou menos. Para Lopes e Alves (2011), trata-se de um grande desafio literário, pois é preciso sintetizar a história e ao mesmo tempo, contá-la. Há um projeto apresentado 
em um site, intitulado A casa de mil portas, onde se encontram diversos microcontos criados por inúmeros autores.

Rocha (2013), afirma que tais tipos reduzidos de narrar uma história, formam uma literatura adjetivada como "minimalista", pois procura usar o essencial, o mínimo necessário para despertar sentidos e envolver o leitor, porém, trata-se de algo complexo. Ainda, "A micronarrativa ou microliteratura é formada por elementos do nosso tempo: velocidade, condensação e veiculação em painéis eletrônicos e celulares" (ROCHA, 2013, p. 32).

Rocha (2013, p. 32) elenca alguns autores que transitam no campo da microliteratura: Jorge Luis Borges, Julio Cortázar, Millôr Fernandes, Dalton Trevisan e, citando Drummond, Hemingway e João Cabral, acerca do microconto, nos lembra que "escrever é cortar palavras"(DRUMMOND) e "corte todo o resto e fique na essência" (Hemingway), e João Cabral "enxugar até a morte" (João Cabral). Logo, a arte de contar, seja na forma escrita ou oral, pressupõe elaborar a história de forma o mais próximo possível da realidade que se quer construir ou narrar. $\mathrm{O}$ efeito de sentidos se dará com a escolha certa dos elementos que comunicam a história, seja em sua forma verbal ou não verbal. Logo, pode-se afirmar que 'menos é mais'.

Rocha (2013, p. 33) afirma que, atualmente, é possível encontrar os microcontos em [...] camisetas, adesivos, postes, muros, tatuagens, cartão postal, hologramas, desenhos animados e podem ser lidos nos ônibus e metrôs, nos celulares e nas telas de computador.

Desse modo, por meio dos minicontos, dos microcontos, dos nanocontos e/ou dos twitcontos, dentre outros tipos de microliteratura/micronarrativa que surgem, em especial, a partir dos ambientes virtuais, é possível realizar atividades a serem utilizadas e apropriadas, estrategicamente, em aulas de Língua Portuguesa, no segmento do Ensino Médio. A seguir, dois exemplos de microconto, disponíveis em ambiente virtual, dos autores Marcio Markendorf e Adriano Salvi, respectivamente: 


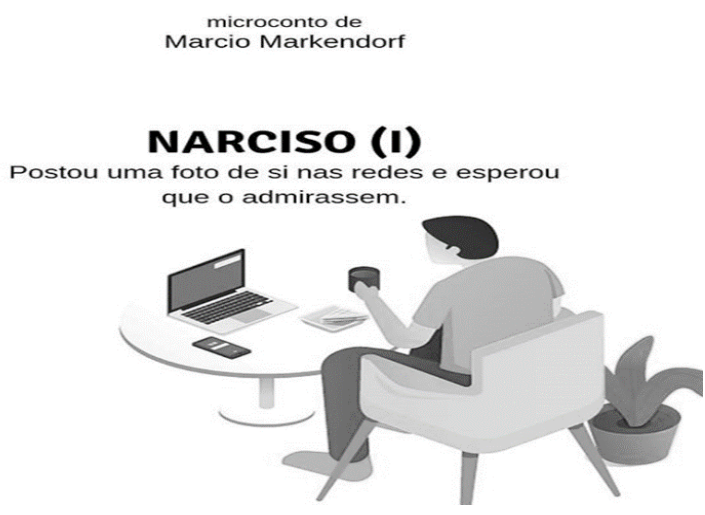

Figura 2. Imagem de microconto

Fonte: Disponível em: encurtador.com.br/dkLV1

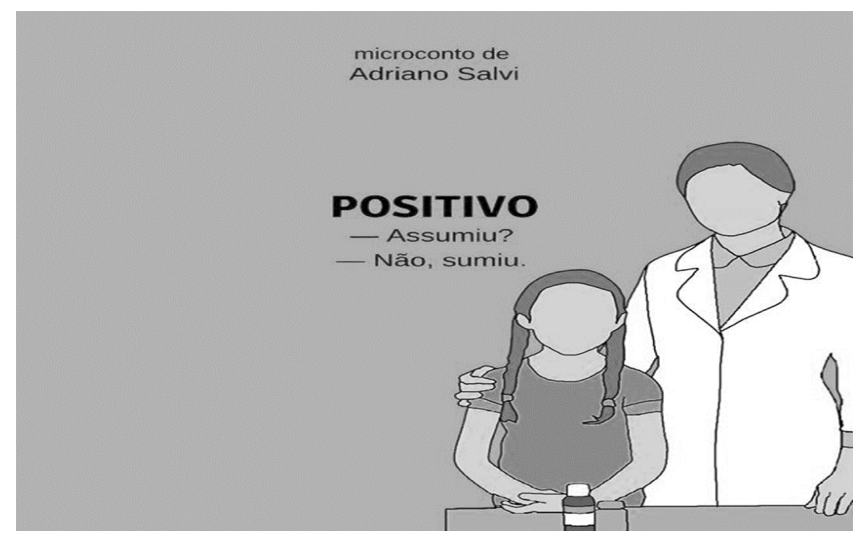

Figura 3. Imagem de microconto

Fonte: Disponível em: encurtador.com.br/bBEF5

Em relação aos microcontos digitais acima apresentados, há de se observar que, por meio da escolha de palavras específicas, juntamente com a atribuição de imagem, os autores conseguem sintetizar uma ideia, um pensamento que se quer provocar no leitor, cabendo a este ponderar sobre a mensagem que lhe pode ser atribuída. O microconto, desse modo, pode direcionar o leitor a uma leitura crítica e reflexiva sobre determinado assunto/situação social/contexto.

No primeiro microconto, a exemplo, o autor leva a pensar sobre a questão da selfie, em uma sociedade cada vez mais individualista, na qual as pessoas, em especial as mais jovens, estão preocupadas em se expor virtualmente, e em parecer sempre belas, felizes e bem sucedidas. Já, no segundo microconto, sugere-se a reflexão 
sobre a questão da assunção de paternidade, que tem sido um grande problema de cunho social, em decorrência da irresponsabilidade de muitos homens que não reconhecem civilmente e afetivamente seus filhos, o que envolve múltiplos fatores sociais e morais.

Enfim, por meio desse tipo de gênero, vislumbra-se ser possível que o professor lance mão de estratégias para envolver seus alunos em produções nas quais, além de muita criatividade, poderão fazer uso dos artefatos tecnológicos já disponíveis, e de multissemioses, ajudando-os, principalmente na construção crítica do pensamento.

\section{ARREMATES ESTRATÉGICOS FINAIS}

Considera-se, a partir do que foi discutido e proposto neste texto, que é possível e urgente considerar a relevância dos estudos dos (multi)letramentos e, em especial, dos multiletramentos, a fim de que se possa compreender que o ensino e a aprendizagem de Língua Portuguesa não pode ser algo dissociado do mundo "real"; requer, para tanto, aprendizado/aquisição de diversos tipos de letramentos que o indivíduo vivencia ao longo de sua formação, e percepção de que não existe apenas uma forma de se conceber e articular o conhecimento e a cultura existentes.

Desse modo, pode-se afirmar que é realmente necessário fazer uso de "estratégias pedagógicas" para a promoção do ensino de Língua Portuguesa em sala de aula. Estratégias, aqui, caminham no sentido de auxiliar o professor a envolver o aluno em suas aulas, oportunizando reflexões que o ajudem a produzir de forma autoral e a analisar criticamente aquilo que lhe é apresentado na forma de conhecimento e informações, em especial nos espaços virtuais. Ainda, na ideia de estratégia compreende-se que seja possível ao professor estabelecer seus objetivos de ensino, de forma que consiga (e)levar suas aulas ao contexto atual, o qual perpassa pela instituição de uma sociedade (ciber)cultural, na qual o uso/interação da/com as tecnologias digitais é algo que já integra, normalmente, o cotidiano dos estudantes do Ensino Médio.

Nesse sentido, como estratégias a serem utilizadas/construídas/integradas pelo professor de Língua Portuguesa, foi aqui apresentada, como sugestão, a inserção dos gêneros textuais digitais nas aulas, a exemplo das narrativas digitais (digital storytelling) e da microliteratura digital. Ambas podem funcionar como uma forma de se fazer uso efetivo e significativo da Língua Portuguesa, de modo que possibilite que o aluno esteja em contato com múltiplas linguagens/semioses, de forma não apenas (multi)letrada, mas, também, multiletrada, a fim de que consiga construir uma 
compreensão macro do meio em que vive, articulando seus pensamentos, sua visão crítica e, consequentemente, se tornando cada vez mais apto ao convívio social, de forma pro(ativa) e profícua em uma sociedade que, é primordialmente, epistêmica.

\section{REFERÊNCIAS}

BAKHTIN, M. (2003). Os estudos literários hoje. In: BAKHTIN, M. Estética da criação verbal. São Paulo: Martins Fontes, p. 358-366.

BRASIL. Linguagens, códigos e suas tecnologias / Secretaria de Educação Básica. - Brasília: Ministério da Educação, Secretaria de Educação Básica (2006).239 p. (Orientações curriculares para o ensino médio; volume 1). Disponível em: $<$ http://portal.mec. gov.br/seb/arquivos/pdf/book_volume_01_internet.pdf> Acesso em: 10 set. 2017.

BRASIL. Lei de Diretrizes e Bases da Educação Nacional. Lei no 9.394 (1996). Brasília-DF, de 20 de dezembro de 1996.

BRASIL. Ministério da Educação. Base Nacional Comum Curricular. (2017) Disponível em: $<$ http://basenacionalcomum.mec.gov.br/images/BNCC_20dez_site.pdf $>$ Acesso em: 27 jan. 2018.

BRASIL. Parâmetros Curriculares Nacionais: ensino médio - linguagens, códigos e suas tecnologias. (1999). Brasília: MEC/SEMT.

BZUNECK, J. A. (2010). Como motivar os alunos: sugestões e práticas. In: BORUCHOVITCH, E; BZUNECK, J. A; GUIMARÃES, S. E. R. (Orgs). Motivação para aprender. Petrópolis, RJ: Vozes.

CARVALHO, G. P. (2006). Uma reflexão sobre a rede MUNDIAL de computadores. Sociedade e Estado. 21 (2): 549-554, Brasília, maio/ago.

CARVALHO, G. S. (2008). As Histórias Digitais: Narrativas no Século XXI. O Software Movie Maker como Recurso Procedimental para a Construção de Narrações. Dissertação de Mestrado em Educação. São Paulo: Universidade de São Paulo.

COUTO. E. S. (2014). Pedagogias das conexões: Compartilhar conhecimentos e construir subjetividades nas redes sociais digitais. In: Facebook e educação: publicar, curtir, compartilhar/ Cristiane Porto; Edméa Santos (Organizadoras). - Campina Grande: EDUEPB, pp. 47-65. 
FREIRE, P. (1987). Pedagogia do Oprimido. Rio de Janeiro, Paz e Terra.

HALL, S. (2006). A identidade cultural na pós-modernidade (11 ${ }^{\mathrm{a}}$. Edição). São Paulo: DP\&A.

KIELING, A. S. K. (2012). Narrativas digitais interativas e o uso da tecnologia como narrador implícito. Revista FAMECOS mídia, cultura e tecnologia. Porto Alegre, v. 19, n. 3, pp. 739-758, setembro/dezembro 2012.

KLEIMAN, A. (1995). Modelos de letramento e as práticas de alfabetização na escola. In: KLEIMAN, A. (Org.). Os significados do letramento: uma nova perspectiva sobre a prática social da escrita. Campinas: Mercado de Letras, p. 15-61.

LÉVY, P. (2010). Cibercultura. Trad. de Carlos Irineu da Costa. $3^{\mathrm{a}}$ ed. - São Paulo: Ed. 34.

LOPES, T. R. C.; ALVES, I. M. R. (2011). Novos meios, novas práticas de ensino-aprendizagem: proposta de produção colaborativa de um twitconto. Revista Renote. Novas Tecnologias na Educação. v. 9, . 2.

MARCUSHI, L.A. (2010). Gêneros textuais emergentes no contexto de tecnologia digital. Em: MARCUSHI, L.A \&XAVIER, A.C. (orgs.) Hipertexto e Gêneros Digitais: novas formas de construção de sentido. $3^{\text {a }}$ ed. São Paulo: Cortez.

OLIVEIRA, J.V.S. (2018). 184 f. il. Dissertação (Mestrado) - Faculdade de Educação, Universidade Federal da Bahia, Salvador.

PAIVA, V. L. M. O. (2016). A linguagem dos emojis. Trab. linguist. apl. [online]. vol. 55, n.2, pp. 379-401. Disponível em:<http://www.scielo.br/pdf/tla/v55n2/0103-1813tla-55-02-00379.pdf > Acesso em: Acesso em: 09 nov. 2019.

ROCHA, A. A. C. O. M. (2013) MICROCONTO - NOVO GÊNERO textual. Monografia (Pós-Graduação) - Universidade Católica de Brasília, Brasília.

ROJO, R. H.; MOURA, E. (Orgs.). (2012) Multiletramentos na Escola. São Paulo: Parábola Editorial.

ROJO, R. H.; BARBOSA, J. (2015). Hipermodernidade, Multiletramentos e Gêneros Discursivos. São Paulo: Parábola Editorial.

ROSSATTO, E. (2010). Cem todues cravados. São Paulo: Andross.

SILVA, O. S. F. (2008). Tessituras (Hiper) textuais: leitura e escrita nos cenários digitais. Salvador: Quarteto. 
SILVA, O. S. F. (2017). (Multi)letramentos e formação de professores na sociedade digital: entretecendo (desa)fios. In: ALVES, Lynn e MOREIRA, J. António.(Orgs.) Tecnologias \& aprendizagens: delineando novos espaços de interação. Salvador: EDUFBA, p. 213-241.

SILVA, S. B. B. (2019) Língua e tecnologias de aprendizagem na escola. In: Educação, (multi)letramentos e tecnologias: tecendo redes de conhecimento sobre letramentos, cultura digital, ensino e aprendizagem na cibercultura / Obdália Ferraz, organizadora. - Salvador: EDUFBA, pp. 189-204.

SOARES, M. (2005) Letramento: um tema em três gêneros. Belo Horizonte: Autêntica Editora.

SOARES, M. (2002). Novas Práticas de Leitura e Escrita: letramento na cibercultura. Educ. Soc., Campinas, vol. 23, n. 81, p. 143-160, dez. Disponível em: < http://www.scielo.br/ pdf/es/v23n81/13935.pdf. >Acesso em 10 jan. 2016.

STREET, B. V. (2014). Letramentos sociais: abordagens críticas do letramento no desenvolvimento, na etnografia e na educação. Trad. Marcos Bagno. São Paulo: Parábola Editorial.

VALENTE, J. A.; ALMEIDA, M. E. B. (2014). Narrativas digitais e o estudo de contextos de aprendizagem. Em Rede, Revista de Educação a Distância, 1(1), 32-50. Disponível em: $<$ file:///C:/Users/Jurene\%20Veloso/Downloads/10-75-1-PB.pdf> Acesso em: 16 set. 2018.

Recebido: $16 / 7 / 2020$

Aceito: $12 / 9 / 2020$

Publicado: 6/10/2020 